OPEN ACCESS

Edited by: Peter J. Gollan, University of Turku, Finland

Reviewed by: Alessandro Alboresi, University of Padua, Italy

Martina Jokel-Toivanen, University of Turku, Finland

*Correspondence: Chikahiro Miyake cmiyake@hawk.kobe-u.ac.jp

tThese authors have contributed equally to this work and share first authorship

Specialty section: This article was submitted to Plant Metabolism and Chemodiversity, a section of the journal Frontiers in Plant Science

Received: 17 February 2021 Accepted: 30 July 2021 Published: 19 August 2021

Citation: Shimakawa G, Hanawa H, Wada S, Hanke GT, Matsuda Y and Miyake C (2021) Physiological Roles of Flavodiiron Proteins and Photorespiration in the Liverwort Marchantia polymorpha.

Front. Plant Sci. 12:668805. doi: $10.3389 / f p / s .2021 .668805$

\section{Physiological Roles of Flavodiiron Proteins and Photorespiration in the Liverwort Marchantia polymorpha}

\author{
Ginga Shimakawa $a^{1,2,3,4 t}$, Hitomi Hanawa ${ }^{1 t}$, Shinya Wada ${ }^{1,4}$, Guy T. Hanke ${ }^{5}$, \\ Yusuke Matsuda ${ }^{3}$ and Chikahiro Miyake ${ }^{1,4 *}$
}

${ }^{1}$ Graduate School of Agricultural Science, Kobe University, Kobe, Japan, ${ }^{2}$ Research Center for Solar Energy Chemistry, Osaka University, Suita, Japan, ${ }^{3}$ Department of Biosciences, School of Biological and Environmental Sciences, KwanseiGakuin University, Nishinomiya, Japan, ${ }^{4}$ Core Research for Environmental Science and Technology, Japan Science and Technology Agency, Chiyoda, Japan, ${ }^{5}$ School of Biochemistry and Chemistry, Queen Mary University of London, London, United Kingdom

Against the potential risk in oxygenic photosynthesis, that is, the generation of reactive oxygen species, photosynthetic electron transport needs to be regulated in response to environmental fluctuations. One of the most important regulations is keeping the reaction center chlorophyll (P700) of photosystem I in its oxidized form in excess light conditions. The oxidation of P700 is supported by dissipating excess electrons safely to $\mathrm{O}_{2}$, and we previously found that the molecular mechanism of the alternative electron sink is changed from flavodiiron proteins (FLV) to photorespiration in the evolutionary history from cyanobacteria to plants. However, the overall picture of the regulation of photosynthetic electron transport is still not clear in bryophytes, the evolutionary intermediates. Here, we investigated the physiological roles of FLV and photorespiration for P700 oxidation in the liverwort Marchantia polymorpha by using the mutants deficient in FLV (flv1) at different $\mathrm{O}_{2}$ partial pressures. The effective quantum yield of photosystem II significantly decreased at $2 \mathrm{kPa} \mathrm{O}$ in $f / v 1$, indicating that photorespiration functions as the electron sink. Nevertheless, it was clear from the phenotype of flv1 that FLV was dominant for P700 oxidation in M. polymorpha. These data suggested that photorespiration has yet not replaced FLV in functioning for P700 oxidation in the basal land plant probably because of the lower contribution to lumen acidification, compared with FLV, as reflected in the results of electrochromic shift analysis.

Keywords: P700 oxidation, photosynthesis, photorespiration, evolution, oxygen

\section{INTRODUCTION}

To survive natural environmental fluctuations, oxygenic phototrophs have developed a variety of regulatory mechanisms for photosynthetic electron transport. Among these, photoprotection of photosystem I (PSI) is critically important. Without such protection, photo-oxidative damage to PSI derived from reactive oxygen species (ROS) dramatically decreases photosynthetic $\mathrm{CO}_{2}$ assimilation and growth rates (Sejima et al., 2014; Zivcak et al., 2015; Shimakawa et al., 2016). Oxidation of the reaction center chlorophyll of PSI, P700, is the universal strategy to suppress 
ROS production at the electron acceptor side of PSI in excess light conditions, which is regulated by a variety of molecular mechanisms, defined as the "P700 oxidation system" (Shimakawa and Miyake, 2018b). First, the suppression of electron transport at the cytochrome (Cyt) $b_{6} f$ complex contributes to P700 oxidation. The mechanism for this is either through a difference in the proton concentration across thylakoid membrane $(\Delta \mathrm{pH})$ dependent mechanism, by the so-called photosynthetic control (Foyer et al., 1990; Kramer et al., 2003), or through the proposed mechanism dependent on reduced plastoquinone (PQ) pool, termed as RISE (Shaku et al., 2016). Second, an electron sink is required as a prerequisite for P700 oxidation. The electron carrier protein ferredoxin (Fd) transfers the majority of electrons from PSI to the ferredoxin: $\mathrm{NADP}(\mathrm{H})$ oxidoreductase (FNR) for reduction of $\mathrm{NADP}^{+}$to NADPH. The dominant electron sink for $\mathrm{NADPH}$ is photosynthetic $\mathrm{CO}_{2}$ assimilation in the Calvin-Benson-Bassham cycle, which is initiated by the carboxylation reaction of ribulose $1-5$ bisphosphate (RuBP) to two molecules of glyceraldehyde 3-phosphate (PGA) by RuBP carboxylase/oxygenase (Rubisco). Also, Rubisco catalyzes the oxygenation reaction of $\mathrm{RuBP}$ to generate PGA and 2-phosphoglycolate. The latter one is finally converted to PGA with reduced Fd and ATP in the so-called photorespiration. Photorespiration can therefore function as an electron sink to keep P700 oxidized in $\mathrm{C}_{3}$ plants (Furutani et al., 2020b). Flavodiiron proteins (FLV) also function as an alternative electron sink at PSI by transferring electrons from reduced Fd to $\mathrm{O}_{2}$ in excess light conditions (Helman et al., 2003; Sétif et al., 2020). Proton gradient regulation 5 (PGR5) and PGR5like 1 (PGRL1) proteins are required for P700 oxidation but their physiological roles are still elusive (Munekage et al., 2002; DalCorso et al., 2008; Mosebach et al., 2017; Rantala et al., 2020).

The dominant contributors to P700 oxidation have changed over the evolutionary history of the so-called photosynthetic green plastid lineage from cyanobacteria to angiosperms (Shimakawa and Miyake, 2018b; Alboresi et al., 2019). Cyanobacteria, the progenitors of oxygenic photosynthesis, predominantly keep P700 oxidized either by RISE or FLV in excess light conditions, such as fluctuating light and $\mathrm{CO}_{2}$ limitation (Allahverdiyeva et al., 2013; Shimakawa et al., 2016). Cyanobacterial genomes encode a homolog of PGR5, but the knockout mutant shows only a minor photosynthetic phenotype (Allahverdiyeva et al., 2013; Sétif et al., 2020), while Dann and Leister reported that cyanobacterial PGR5 functions as plant PGR5 and also as plant PGRL1 (Dann and Leister, 2019). Further, it has been suggested that the cyanobacterial PGR5 homolog is related to redox homeostasis based on a study in which the gene was over-expressed (Margulis et al., 2020). By contrast, the green alga Chlamydomonas reinhardtii shows a strong impact of PGR5 on the $\Delta \mathrm{pH}$-dependent regulation for P700 oxidation (Johnson et al., 2014; Mosebach et al., 2017; Jokel et al., 2018; Nikkanen et al., 2021). FLV is also important as an electron sink in the green alga (Chaux et al., 2017; Nikkanen et al., 2021), but the genes for FLV are no longer conserved in the genomes of angiosperms (Allahverdiyeva et al., 2015). Genes for photorespiratory metabolism are broadly conserved in photosynthetic organisms (Hagemann et al., 2013), but the in vivo activity of photorespiration is negligible in cyanobacteria and many eukaryotic algae (Peltier and Thibault, 1985; Badger et al., 2000). Overall, the clear evidence that photorespiration contributes to P700 oxidation has been only observed in $\mathrm{C}_{3}$ plants. Angiosperms strongly rely on photosynthetic control following lumen acidification for P700 oxidation, which is supported by PGR5, PGRL1, and chloroplast NAD(P)H dehydrogenase (Munekage et al., 2002; Suorsa et al., 2012; Yamori et al., 2016; Rantala et al., 2020). One important change from cyanobacteria to angiosperms in the strategy for P700 oxidation is that FLV has been functionally replaced with photorespiration as the dominant electron sink.

Basal land plants, including liverworts, mosses, ferns, and gymnosperms, are assumed to develop the intermediary strategy to keep P700 oxidized between green algae and angiosperms (Shimakawa and Miyake, 2018b; Alboresi et al., 2019). In these land plants, photorespiration keeps photosynthetic linear electron flow at the $\mathrm{CO}_{2}$-compensation point (Hanawa et al., 2017), whereas FLV functions for this in cyanobacteria (Shimakawa et al., 2016; Santana-Sanchez et al., 2019). Recently, Storti and co-workers reported that in the moss Physcomitrium patens the lack of PGRL1 has little effect on photoprotection except when combined with a mutation in the gene for FLV, which results in photo-oxidative damage of PSI, especially under fluctuating light (Storti et al., 2019; Storti et al., 2020). The PGR5- and PGRL1-dependent regulatory mechanism is therefore assumed to be dispensable for P700 oxidation in the presence of the electron sink mediated by FLV as in the cases that a heterologous expression of FLV complements P700 oxidation in the mutants of Arabidopsis thaliana and Oryza sativa deficient in PGR5 (Yamamoto et al., 2016; Wada et al., 2018). However, in contrast to $\mathrm{C}_{3}$ angiosperms, the contribution of photorespiration to P700 oxidation is poorly understood in these basal land plants.

Here, we sought to investigate the impact of the $\mathrm{O}_{2}$-dependent electron sink, i.e., FLV and photorespiration on P700 oxidation in the liverwort Marchantia polymorpha, which is positioned between algae and plants in the photosynthetic green plastid lineage (Bowman et al., 2007). One of the habitats of M. polymorpha is the marginal area between aquatic and land environments; thus, this plant must anticipate both submergence and drought stress, which presumably exposes $M$. polymorpha to fluctuating $\mathrm{O}_{2}$ and $\mathrm{CO}_{2}$ availability, because the diffusion coefficient of gasses in water is approximately $10^{-4}$ times lower than that in the atmosphere (Raven et al., 1985; Badger and Spalding, 2000). As already mentioned above, $M$. polymorpha utilizes both photorespiration and FLV as alternative electron sinks, probably depending on $\mathrm{O}_{2}$ availability, because the affinity of Rubisco for $\mathrm{O}_{2}\left(K_{\mathrm{m}}\right.$ is $300-1,500 \mu \mathrm{m}$ at $\left.25^{\circ} \mathrm{C}\right)$ is presumably much lower than that of FLV $\left(K_{\mathrm{m}}\right.$ is assumed to be $<10 \mu \mathrm{m}$; Vicente et al., 2002; Orr et al., 2016). A variety of photosynthetic parameters, including chlorophyll fluorescence, P700 absorbance, and the thylakoid membrane potential, was measured at atmospheric $(21 \mathrm{kPa})$ and low $(2 \mathrm{kPa}) \mathrm{O}_{2}$ conditions in the $M$. polymorpha wild type (Tak-1) and the mutant deficient in FLV1 $(f l v 1)$ to assess the physiological functions of these molecular mechanisms in regulating photosynthetic electron transport in the basal land plant. 


\section{MATERIALS AND METHODS}

\section{Culture}

A male accession of $M$. polymorpha, Takaragaike (Tak)-1 and the mutant deficient in FLV1 were asexually maintained according to previously described methods (Shimakawa et al., 2017). Tak-1 and each mutant were grown on one-half-strength Gamborg's B5 agar medium (Gamborg et al., 1968) under a light-dark cycle ( $14 \mathrm{~h}$ light, $22^{\circ} \mathrm{C}, 100 \mu \mathrm{mol}$ photons $\mathrm{m}^{-2} \mathrm{~s}^{-1}$, white fluorescent lamp $/ 10 \mathrm{~h}$ dark, $20^{\circ} \mathrm{C}$ ). For biochemical and physiological measurements, 2-week-old gemmalings were transferred from B5 agar medium into moist vermiculite, and they were grown there for further 2 weeks. For the treatment with aminoacetonitrile (AAN), the thalli were floated on tap water with and without $10 \mathrm{~mm}$ aminoacetonitrile for $3 \mathrm{~h}$.

\section{Oxygen Exchange}

Oxygen evolution and uptake of thalli of $M$. polymorpha $\left(2-5 \mathrm{~cm}^{2}\right)$ were measured in an $\mathrm{O}_{2}$ electrode chamber (LD2/3; Hansatech, King's Lynn, United Kingdom) simultaneously with chlorophyll fluorescence using a Junior-PAM chlorophyll fluorometer (Walz, Effeltrich, Germany). Temperature of the chamber was set to $25^{\circ} \mathrm{C}$. Red actinic light was illuminated from the top of the chamber (LH36/2R; Hansatech). Since the $\mathrm{O}_{2}$ electrode chamber was a closed system, a $\mathrm{CO}_{2}$-saturated condition was simulated by placing a fabric mat wetted with $1 \mathrm{M} \mathrm{NaHCO}_{3}$ solution below the intact thalli to supply $\mathrm{CO}_{2}$ at a concentration of approximately $1 \mathrm{kPa}$.

\section{Chlorophyll Fluorescence, P700 Absorbance, and ECS}

Chlorophyll fluorescence, absorbance of oxidized P700 $\left(\mathrm{P} 700^{+}\right)$, and electrochromic shift (ECS) were measured using a DualPAM-100 in a 3,010 DUAL gas exchange leaf chamber (Walz). Flowed gasses were saturated with water vapor at $16.0 \pm 0.1^{\circ} \mathrm{C}$, and the thalli temperature was maintained at $25^{\circ} \mathrm{C}$. Ambient air was used for the measurement at atmospheric $\mathrm{O}_{2}(21 \mathrm{kPa})$ conditions. For the measurement at low $\mathrm{O}_{2}$, the standard $\mathrm{O}_{2}$ gas at $2 \mathrm{kPa}$ in $\mathrm{N}_{2}$ was mixed with $1 \mathrm{kPa} \mathrm{CO}_{2}$ in $\mathrm{N}_{2}$ to keep the atmospheric $\mathrm{CO}_{2}$ level (approximately $40 \mathrm{~Pa}$ ) in an LI-7000 infrared gas analyzer (Li-COR, Lincoln, United States). Before the measurements, the thalli were adapted to the darkness for $5 \mathrm{~min}$.

For chlorophyll fluorescence analysis, a pulse-amplitude modulated red measuring light $(620 \mathrm{~nm}, 0.08 \mu \mathrm{mol}$ photons $\mathrm{m}^{-2} \mathrm{~s}^{-1}$ ) was used (Schreiber et al., 1986; Genty et al., 1989; Baker, 2008). PSII operating efficiency (quantum yield of photochemical energy conversion in PSII), $\mathrm{Y}(\mathrm{II})=\left(\mathrm{F}_{\mathrm{m}}{ }^{\prime}-\mathrm{F}^{\prime}\right)$ / $\mathrm{F}_{\mathrm{m}}{ }^{\prime}$; non-photochemical quenching $(\mathrm{NPQ}), \mathrm{NPQ}=\left(\mathrm{F}_{\mathrm{m}}-\mathrm{F}_{\mathrm{m}}{ }^{\prime}\right) /$ $\mathrm{F}_{\mathrm{m}}{ }^{\prime}$; fraction of "open" PSII centers (with $\mathrm{Q}_{\mathrm{A}}$ oxidized) on the basis of the lake model for the PSII photosynthetic apparatus, $\mathrm{qL}=\left[\left(\mathrm{F}_{\mathrm{m}}{ }^{\prime}-\mathrm{F}^{\prime}\right) /\left(\mathrm{F}_{\mathrm{m}}{ }^{\prime}-\mathrm{F}_{\mathrm{o}}{ }^{\prime}\right)\right] \times\left(\mathrm{F}_{\mathrm{o}}{ }^{\prime} / \mathrm{F}^{\prime}\right): \mathrm{F}_{\mathrm{o}}$, minimum fluorescence from dark-adapted thalli; $\mathrm{F}_{\mathrm{o}}{ }^{\prime}$, minimum fluorescence from lightadapted thalli; $F_{m}$, maximum fluorescence from dark-adapted thalli; and $\mathrm{F}_{\mathrm{m}}$ ', maximum fluorescence from light-adapted thalli. Red actinic light was supplied using a chip-on-board light emitting diode (LED) array $(635 \mathrm{~nm})$. Short-saturation pulse light $\left(8,000 \mu \mathrm{mol}\right.$ photons $\left.\mathrm{m}^{-2} \mathrm{~s}^{-1}, 300 \mathrm{~ms}\right)$ was also provided by the LED array for the determinations of $F_{m}$ and $F_{m}$ '.

Pulse-amplitude modulated near-infrared measuring lights (830 and $870 \mathrm{~nm})$ were applied to measure the transmittance of $\mathrm{P} 700^{+}$(Harbinson and Woodward, 1987; Klughammer and Schreiber, 1994). The full oxidation level of P700 was determined by the $300-\mathrm{ms}$ short-saturation flash after 1-s far-red light illumination $(730 \mathrm{~nm})$, and the full reduction level of P700 was defined in the dark. P700 oxidation was evaluated as the ratio of $\mathrm{P} 700^{+}$to the total $\mathrm{P} 700$ signal in the light.

ECS was measured with a pulse-amplitude modulated green measuring light (515 and $550 \mathrm{~nm}$ ) using a Dual-PAM-100 fluorometer equipped with a P515-analysis module (Baker et al., 2007; Klughammer et al., 2013). Change in ECS amplitude in the transition from light to dark, reflecting proton motive force, was termed as $\mathrm{ECS}_{\text {total }}$, which was measured by temporarily turning actinic light off for $600 \mathrm{~ms}$ during the illumination. The $\mathrm{ECS}_{\text {total }}$ values were normalized by the magnitude of ECS induced by a 5 - $\mu$ s short-saturation flash (Klughammer et al., 2013). Proton conductance of the chloroplast ATP synthase $\left(g_{\mathrm{H}}{ }^{+}\right)$was calculated as the rate constant of the mono-exponential decay of ECS in the transition from light to dark (Sacksteder and Kramer, 2000).

\section{RESULTS}

\section{Effects of FLV and Photorespiration on Chlorophyll Fluorescence in M. polymorpha}

In M. polymorpha, FLV functions to keep P700 oxidized. Since FLV can mask the effect of photorespiration on P700 oxidation, here, we used the mutant deficient in FLV ( $l v 1)$ that was generated in our previous study in comparison with the wildtype Tak-1 (Shimakawa et al., 2017). There was no difference in net $\mathrm{O}_{2}$ evolution rate between Tak-1 and $f l v 1$ in a $\mathrm{CO}_{2}$ saturated condition, where photorespiration should not occur, indicating that FLV has no direct impact on photosynthetic $\mathrm{CO}_{2}$ assimilation (Shimakawa et al., 2017).

Here, we analyzed the in vivo chlorophyll fluorescence of Tak- 1 and $f l v 1$ at atmospheric $\mathrm{CO}_{2}$ partial pressure (approximately $40 \mathrm{~Pa})$ in atmospheric $(21 \mathrm{kPa})$ and low $(2 \mathrm{kPa}) \mathrm{O}_{2}$ conditions. In the atmospheric $\mathrm{CO}_{2}$ condition, Rubisco can catalyze the oxygenation of RuBP dependent on the decrease of available $\mathrm{CO}_{2}$, driving photorespiration. Because the affinity of Rubisco with $\mathrm{O}_{2}$ is low $\left(K_{\mathrm{m}}\right.$ is $300-1,500 \mu \mathrm{m}$ at $25^{\circ} \mathrm{C}$; Orr et al., 2016), photorespiration should be largely inhibited at $2 \mathrm{kPa} \mathrm{O}_{2}$ in $M$. polymorpha. Compared with Rubisco, FLV is assumed to show a higher affinity with $\mathrm{O}_{2}\left(K_{\mathrm{m}}\right.$ is presumed to be a few $\mu \mathrm{m}$ at $25^{\circ} \mathrm{C}$; Vicente et al., 2002; Romão et al., 2016). However, we note that the FLV-mediated alternative electron transport was partially inhibited at $2 \mathrm{kPa} \mathrm{O}_{2}$ in M. polymorpha (Figure 1). In Figure 2, the representative raw traces of chlorophyll fluorescence are shown. After the chlorophyll fluorescence intensity reached a stationary level, the actinic light intensity was changed every 2 min during the measurements. Compared with Tak-1, flv1 showed the higher fluorescence intensities 


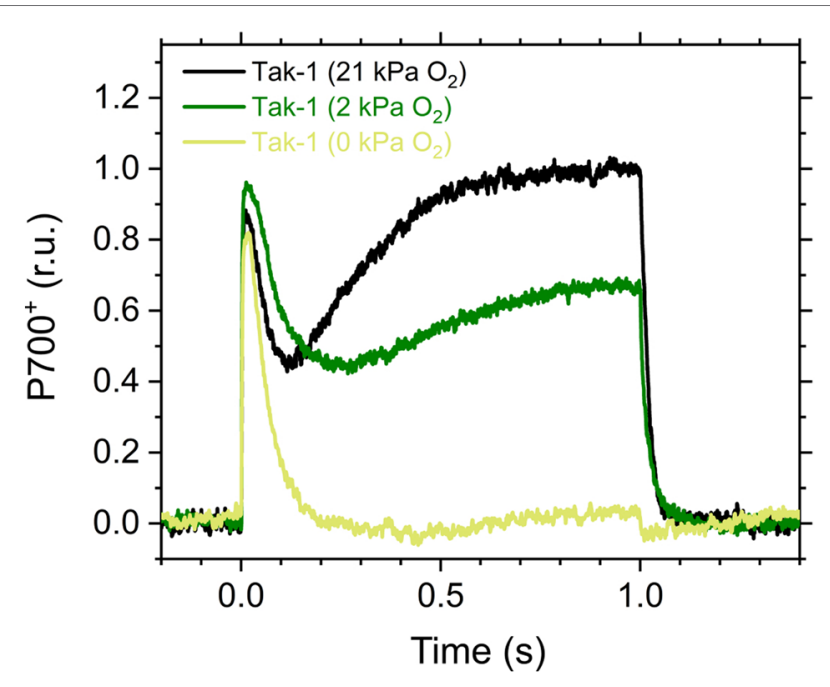

FIGURE 1 | Kinetics of oxidized P700 (P700+) in the illumination with a shortpulse light $\left(2,000 \mu \mathrm{mol}\right.$ photons $\left.\mathrm{m}^{-2} \mathrm{~s}^{-1}, 1 \mathrm{~s}\right)$ in the liverwort Marchantia polymorpha (Tak-1). Experiments were performed under 21 (black), 2 (green), and $\mathrm{OKPaO} \mathrm{O}_{2}$ (light green). Relative $\mathrm{P} 700^{+}$signals are normalized by the maximum oxidation level of P700 as 1.0. Representative traces of the three independent measurements are shown, respectively.

especially in the induction phase of photosynthesis and at high light intensities (Figure 2). That is, the deficit of FLV accumulated electrons at the acceptor side of PSII, especially at $2 \mathrm{kPa} \mathrm{O}_{2}$.

$\mathrm{Y}$ (II) calculated from the chlorophyll fluorescence was lower in $f l v 1$, indicating that FLV functions as the electron sink in M. polymorpha (Shimakawa et al., 2017). Here, we note that even in $f l v 1 \mathrm{Y}(\mathrm{II})$ decreased at $2 \mathrm{kPa} \mathrm{O}_{2}$ (Figures 3A,B), which suggested that photorespiration functions as the electron sink in M. polymorpha (Hanawa et al., 2017). The redox state of the acceptor side of PSII was also evaluated using the chlorophyll fluorescence parameter $\mathrm{qL}$ which infers the oxidation level of the PQ pool. Similar trends to Y(II) were observed in Tak-1 and $f l v 1$ in both atmospheric and low $\mathrm{O}_{2}$ conditions (Figures 3C,D).

Non-photochemical quenching is the chlorophyll fluorescence parameter showing the amplitude of heat dissipation of light energy at PSII and is assumed to have a correlation with $\Delta \mathrm{pH}$ in plant leaves (Kanazawa and Kramer, 2002). In both Tak-1 and $f l v 1$, NPQ slightly increased at $2 \mathrm{kPa} \mathrm{O}_{2}$, compared with $21 \mathrm{kPa} \mathrm{O}_{2}$ (Figures 3E,F). Regardless of the $\mathrm{O}_{2}$ partial pressure, flv1 clearly showed lower NPQ than Tak-1.

\section{Effects of FLV and Photorespiration on P700 Oxidation in M. polymorpha}

We evaluated the redox state of $\mathrm{P} 700$ from in vivo near- infrared absorbance in Tak-1 and $f l v 1$. Whereas Tak-1 kept P700 more oxidized at higher light intensities, flv 1 showed little oxidation of P700 at various light intensities regardless of the $\mathrm{O}_{2}$ partial pressure (Figure 4). This shows that, in the absence of FLV, the rate determination step in electron transport at PSI is at

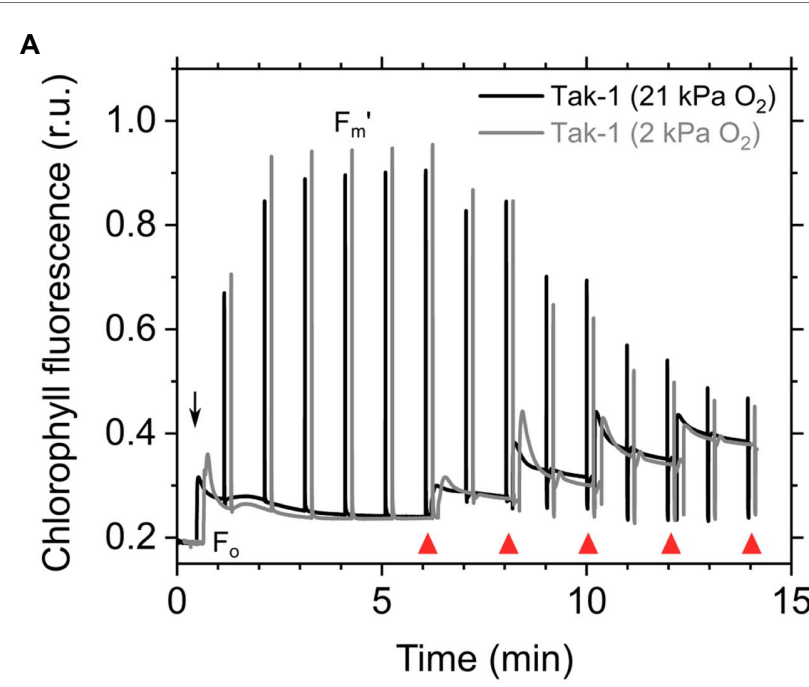

B

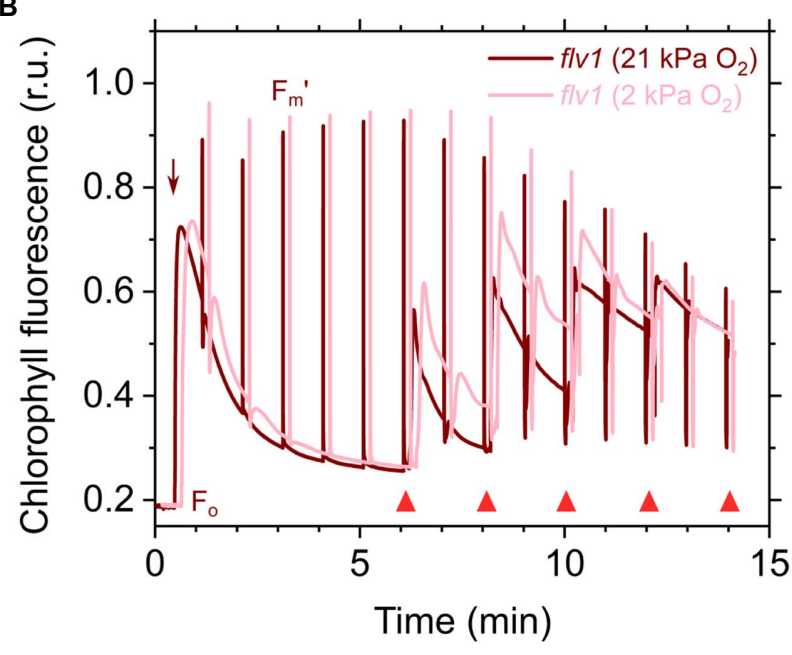

FIGURE 2 | Responses of chlorophyll fluorescence to the light in the liverwort M. polymorpha (Tak-1; A) and the mutant flv1 (B). Experiments were performed under 21 (darker lines) and $2 \mathrm{kPa} \mathrm{O}_{2}$ (lighter lines).

Fluorescence measuring light was illuminated to determine the minimum fluorescence from dark-adapted thalli $\left(F_{0}\right)$. Short-saturation flashes were applied every $1 \mathrm{~min}$ to determine the maximum fluorescence from lightadapted thalli $\left(F_{m}\right)$. Red actinic light was turned on at the time indicated by black arrows, and the light intensities were changed as indicated by red triangles $\left(50,100,200,390\right.$, and $760 \mu \mathrm{mol}$ photons $\left.\mathrm{m}^{-2} \mathrm{~s}^{-1}\right)$. Relative chlorophyll fluorescence intensity is normalized by the maximum fluorescence from a dark-adapted thalli $\left(F_{m}\right)$. Measurements were conducted independently three times (biological replicates), and representative traces are shown.

the acceptor side. However, we note that the prolong illumination at high light intensities promoted P700 oxidation in $f l v 1$ at both 21 and $2 \mathrm{kPa} \mathrm{O}_{2}$, whereas Tak-1 kept almost the constant oxidized level (Figure 5). That is, $f l v 1$ can partially keep P700 oxidize after a certain time in high light conditions even where photorespiration is suppressed (Shimakawa et al., 2017). In $f l v 1$, NPQ also increased during the prolong exposure to high light (Figure 5). 
A

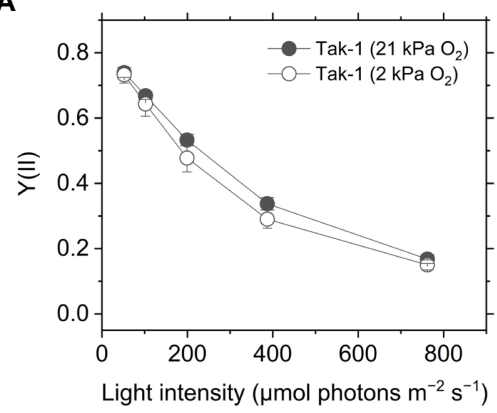

D

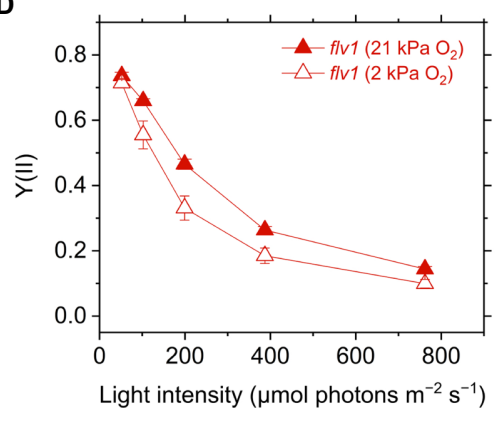

B

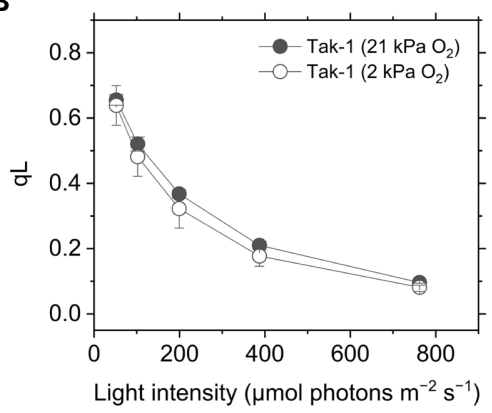

E

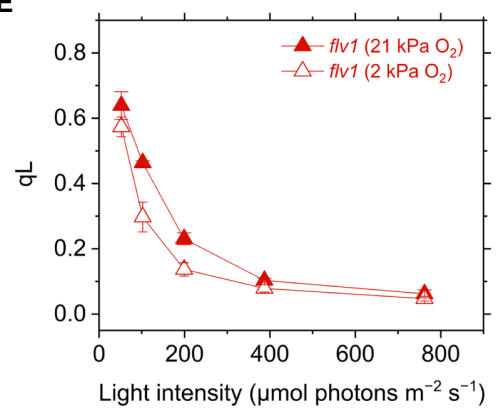

C

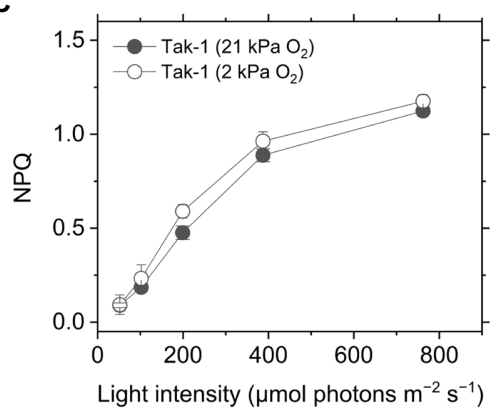

$\mathbf{F}$

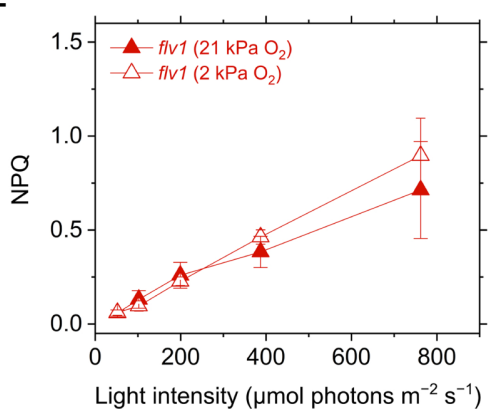

FIGURE 3 | Effective quantum yield of PSII, Y(II) (A,D), inferred oxidation level of plastoquinone pool (qL) (B,E), and non-photochemical quenching (NPQ) of PSII (NPQ; C,F) in the liverwort $M$. polymorpha (Tak-1; A-C) and the mutant flv1 (D-F). Experiments were performed under 21 (closed symbols) and $2 \mathrm{kPa} \mathrm{O}_{2}$ (open symbols). Data are shown as the mean with the standard deviation ( $n=3$, biological replicates).

\section{Effects of FLV and Photorespiration on Thylakoid Membrane Potential in M. polymorpha}

We analyzed the ECS in Tak-1 and $f l v 1$. The ECS signal is considered to be an intrinsic optical voltmeter that rapidly responds to changes in the electrical potential across the thylakoid membrane (Witt, 1979). The thylakoid membrane potential during photosynthesis is defined as the total rapid $(<1 \mathrm{~s})$ change in the ECS signal upon rapidly switching off $\mathrm{AL}$ from the steady state, which includes two components: transmembrane differences in $\Delta \mathrm{pH}$ and in the electric field ( $\Delta \Psi$; Cruz et al., 2001; Johnson and Ruban, 2014). We note that the ECS amplitude depends on the properties of the leaves, not only the density of chloroplasts, but also the content of light-harvesting complexes that house the pigments in which the shift occurs. Therefore, the ECS amplitude was normalized by the magnitude of ECS induced by a 5 - $\mu$ s short- saturation flash, and it was finally termed as ECS 2013). The $f l v 1$ mutant showed a lower ECS total $_{\text {during steady- }}$ state photosynthesis (Figure 6), which is in agreement with the lower Y(II) and NPQ (Figure 3). Proton conductance of the chloroplast ATP synthase, termed as $g_{\mathrm{H}}{ }^{+}$, was also calculated from ECS decay during the transition from light to dark, implying that $f l v 1$ had greater $\mathrm{H}^{+}$leakage from the thylakoid lumen to the stroma than Tak-1 especially at $21 \mathrm{kPa} \mathrm{O}_{2}$ (Figure 6). One thing that should be noted here is that NPQ is also different between Tak-1 and $f l v 1$ (Figure 3), which may lead to the difference in $g_{\mathrm{H}}{ }^{+}$, independent of $\mathrm{H}^{+}$leakage, since the
ECS signal is influenced by the relaxation of NPQ (Johnson and Ruban, 2014).

\section{Effects of FLV and Photorespiration on the Acceptor Side of PSI in M. polymorpha}

Finally, we plotted the P700 oxidation ratio to $1-\mathrm{qL}, \mathrm{NPQ}$, and ECS $_{\text {total }}$ in Tak-1 and $f l v 1$ to assess the mechanism that FLV contributes to P700 oxidation more than photorespiration (Figure 7). Classically, the impairment of P700 oxidation has been evaluated based on the increase of the acceptor-side limitation of PSI, often termed as Y(NA) (Klughammer and Schreiber, 1994). However, it seems to be difficult to precisely determine $\mathrm{Y}(\mathrm{NA})$ and effective quantum yield of PSI, $\mathrm{Y}(\mathrm{I})$, using a near-infrared spectrophotometer because of the fast electron transport between plastocyanin and P700 (see "Discussion"). In this study, we evaluated the impairment of P700 oxidation from its relationship with the inferred reduction state of the PQ pool, 1 - qL (Shimakawa and Miyake, 2018a). Since the electron transport is limited in Cyt $b_{6} f$ complex when P700 is kept oxidized, it is theoretically usual that P700 oxidation has a linear relationship with inferred PQ reduction $(1-\mathrm{qL})$, which was actually recognized in plant leaves and is a useful indicator to evaluate the acceptor side limitation of PSI (Shimakawa and Miyake, 2018a). In $f l v 1$, the inability to keep P700 oxidized was accompanied with the losses of $\mathrm{NPQ}$ and $\mathrm{ECS}_{\text {total }}$, indicating that the $\Delta \mathrm{pH}$-dependent suppression of electron transport in Cyt $b_{6} f$ complex did not function in addition to the loss of the $\mathrm{O}_{2}$-dependent electron sink. 


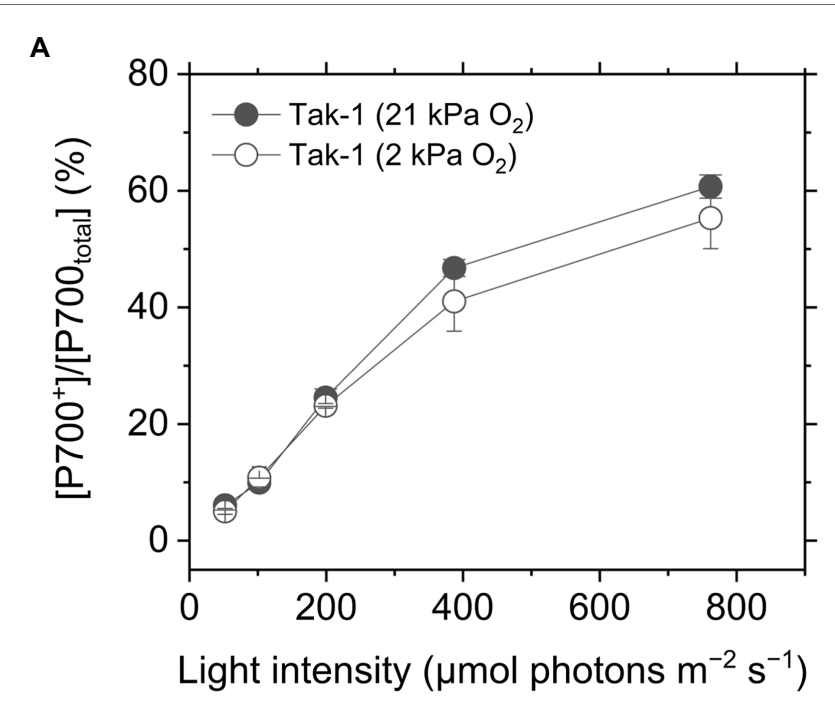

B

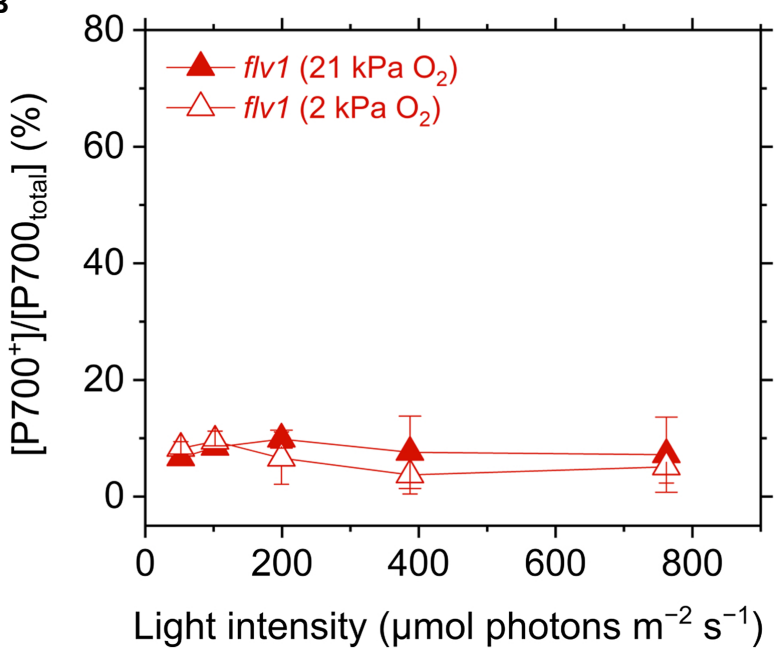

FIGURE 4 | Oxidation of P700 in the liverwort M. polymorpha (Tak-1; A) and the mutant flv1 (B). Experiments were performed under 21 (closed symbols) and $2 \mathrm{kPa} \mathrm{O}_{2}$ (open symbols). Data are shown as the mean with the standard deviation ( $n=3$, biological replicates).

\section{DISCUSSION}

In this study, we investigated the roles of FLV and photorespiration in regulating photosynthetic electron transport in the basal land plant $M$. polymorpha using the mutants deficient in FLV1 and PGR5. As shown in the preceding studies in M. polymorpha and P. patens (Gerotto et al., 2016; Shimakawa et al., 2017; Storti et al., 2019; Storti et al., 2020), FLV is indispensable for keeping P700 oxidized in high light conditions unless the light exposure is prolonged for an acclimation (Figure 5; Shimakawa et al., 2017). Meanwhile, Y(II) and qL decreased at $2 \mathrm{kPa} \mathrm{O}_{2}$ even in $f l v 1$, indicating that there is another $\mathrm{O}_{2}$-dependent electron sink that should be photorespiration (Hanawa et al., 2017). Although we could not evaluate the pure contribution of photorespiration to P700 oxidation because
FLV was also partially inhibited at $2 \mathrm{kPa} \mathrm{O}_{2}$ (Figure 1), the phenotype of $f l v 1$ obviously showed that FLV is dominant for keeping P700 oxidized in M. polymorpha (Figure 4).

Oxygenic phototrophs possess several transport pathways of electrons generated in photosystems to $\mathrm{O}_{2}$. First, photorespiratory $\mathrm{C}_{2}$ cycle needs one reduced $\mathrm{Fd}$ to metabolize one 2-phosphoglycolate generated by the oxygenation reaction of Rubisco and releases each half of molecule of $\mathrm{CO}_{2}$ and PGA that are utilized in the Calvin-Benson cycle (Bauwe et al., 2010). Second, FLV donates electrons from reduced Fd to $\mathrm{O}_{2}$ (Alboresi et al., 2019). Third, electrons at the acceptor side of PSI can reduce $\mathrm{O}_{2}$ also through the Mehler reaction (Miyake, 2010). Fourth, plastid terminal oxidase donates electrons from plastoquinol to $\mathrm{O}_{2}$ (Nawrocki et al., 2015). Finally, the mitochondrial respiration possibly functions as an electron sink for photosynthetic electron transport in chloroplasts (Selinski and Scheibe, 2019) although it remains to be assessed in bryophytes. Based on the in vivo studies using quantitative gas exchange analyses, photorespiration and FLV have the electron sink capacities enough to replace the Calvin-Benson cycle in various oxygenic phototrophs, including cyanobacteria, green algae, and $\mathrm{C}_{3}$ plants at least non-stress conditions (Helman et al., 2005; Driever and Baker, 2011; Allahverdiyeva et al., 2013; Chaux et al., 2017; Burlacot et al., 2018; Santana-Sanchez et al., 2019). Also in bryophytes, Aro and co-workers have found that a large part (ca. 70\%) of electron flux to $\mathrm{O}_{2}$ is attributed to photorespiration (Aro et al., 1984), and the other contributor should be FLV based on the recent knowledges (Gerotto et al., 2016; Shimakawa et al., 2017). Further, the photorespiratory activity has been characterized also by analyzing post-illumination $\mathrm{O}_{2}$ uptake at a $\mathrm{CO}_{2}$-compensation point in $M$. polymorpha (Hanawa et al., 2017). Therefore, here, we concluded that the decrease of $\mathrm{Y}(\mathrm{II})$ at $2 \mathrm{kPa} \mathrm{O}_{2}$ in $f l v 1$ was attributed to the inhibition of photorespiration. We also tried to inhibit photorespiration using a specific inhibitor aminoacetonitrile (Cho et al., 1985). However, the treatment of the $M$. polymorpha thalli with AAN decreased $\mathrm{Y}$ (II) even in a high $\mathrm{CO}_{2}$ condition (Supplementary Figure S1) probably due to the accumulation of photorespiratory intermediates toxic to the Calvin-Benson cycle enzymes (Dellero et al., 2016). Therefore, we sought to suppress photorespiration by changing $\mathrm{O}_{2}$ partial pressure from 21 to $2 \mathrm{kPa}$ in the present study.

Different from $\mathrm{C}_{3}$ plants, photorespiration is not dominant for P700 oxidation although it functions as the electron sink in $M$. polymorpha. The extent of the decrease of Y(II) in flv1 at $2 \mathrm{kPa} \mathrm{O}$ was similar to that by the lack of FLV (Figure 3). Rather, photorespiration has the larger electron sink capacity than FLV under $\mathrm{CO}_{2}$ limitation (Aro et al., 1984; Hanawa et al., 2017). Nevertheless, it has been clearly shown that FLV is essential for P700 oxidation in $M$. polymorpha (Figure 4). One of the most plausible reason is that FLV does not consume ATP, different from photorespiration, and should contribute to producing $\Delta \mathrm{pH}$ more than photorespiration, which induces the suppression of electron transport in Cyt $b_{6} f$ complex to support P700 


\section{A}

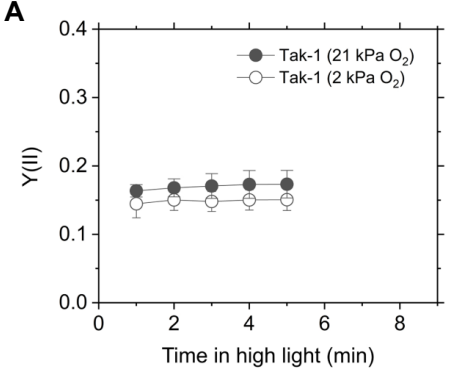

D

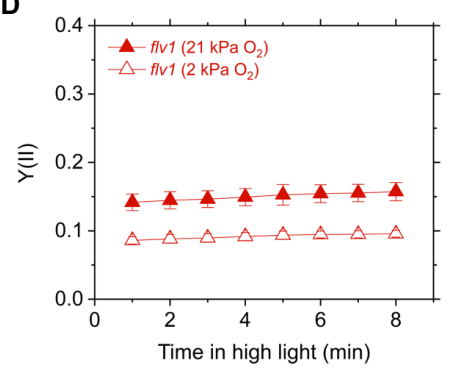

B

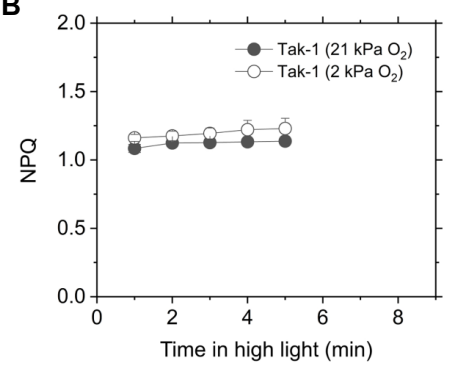

E

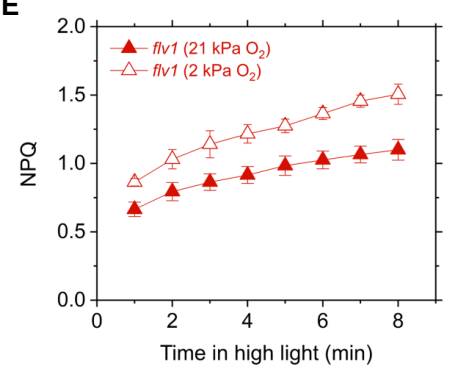

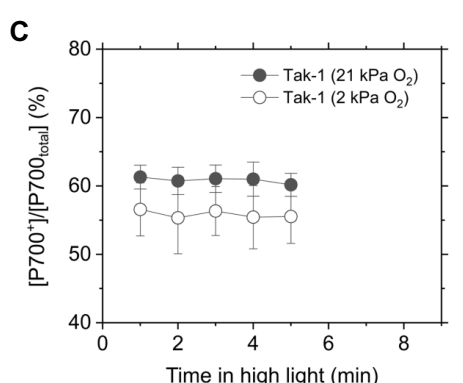

$\mathbf{F}$

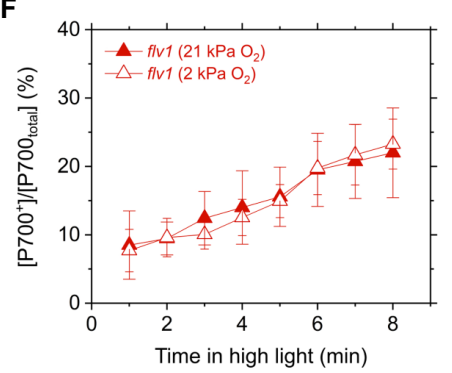

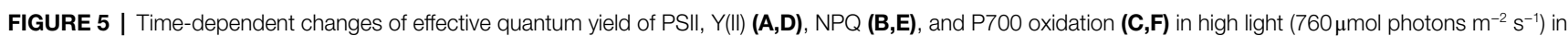
the liverwort M. polymorpha (Tak-1; A-C) and the mutant flv1 (D-F). Experiments were performed under 21 (closed symbols) and $2 \mathrm{kPa} \mathrm{O}_{2}$ (open symbols). Data are shown as the mean with the standard deviation ( $n=3$, biological replicates).

A

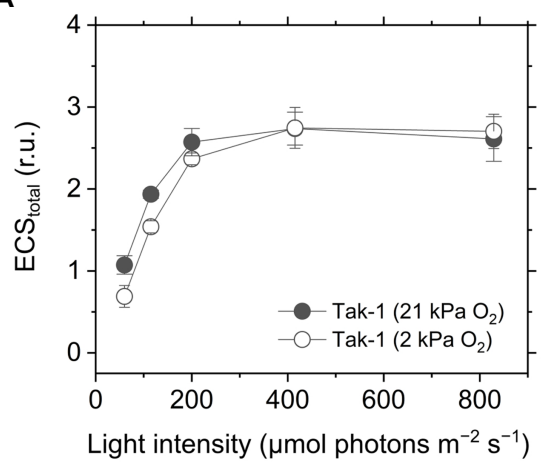

C

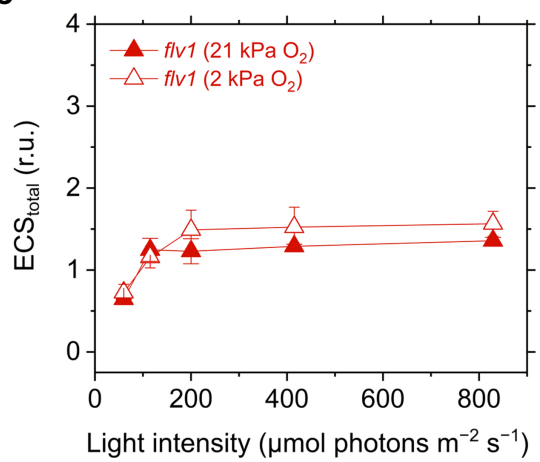

B

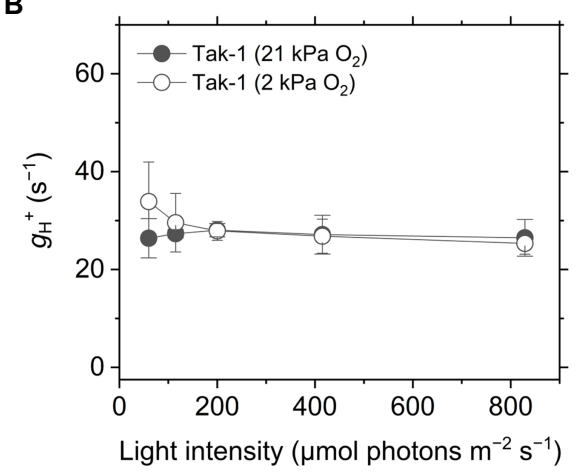

D

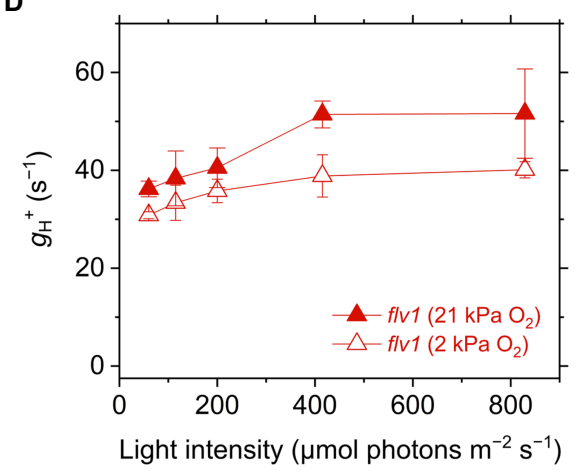

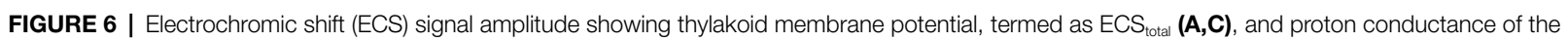
chloroplast ATP synthase, termed as $g_{H}{ }^{+}$(B,D), in the liverwort M. polymorpha (Tak-1; A,B) and the mutant $f / v 1$ (B,D). The relative ECS values were normalized by the ECS amplitude induced by 5 - $\mu$ s short-saturation flash. Experiments were performed under 21 (closed symbols) and $2 \mathrm{kPa} \mathrm{O}_{2}$ (open symbols). Data are shown as the mean with the standard deviation ( $n=3$, biological replicates). 


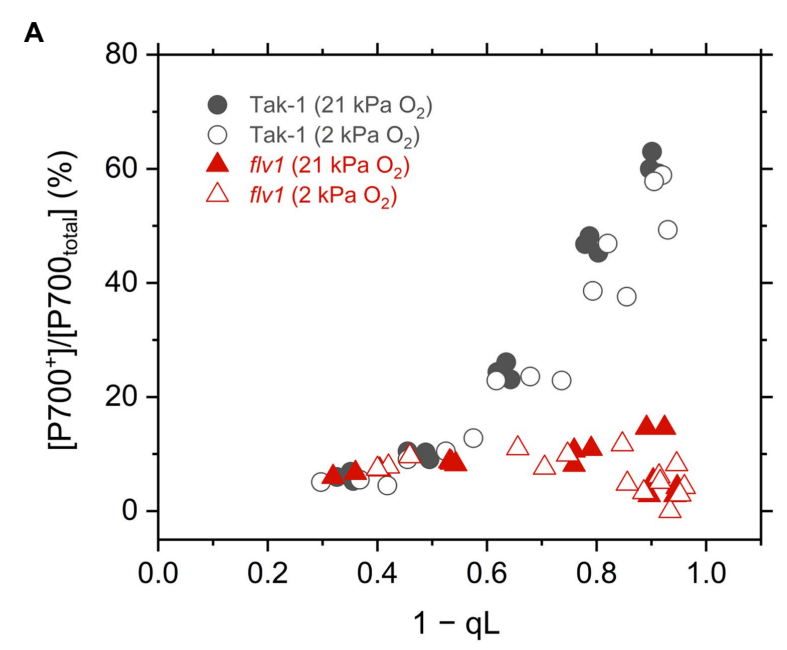

B

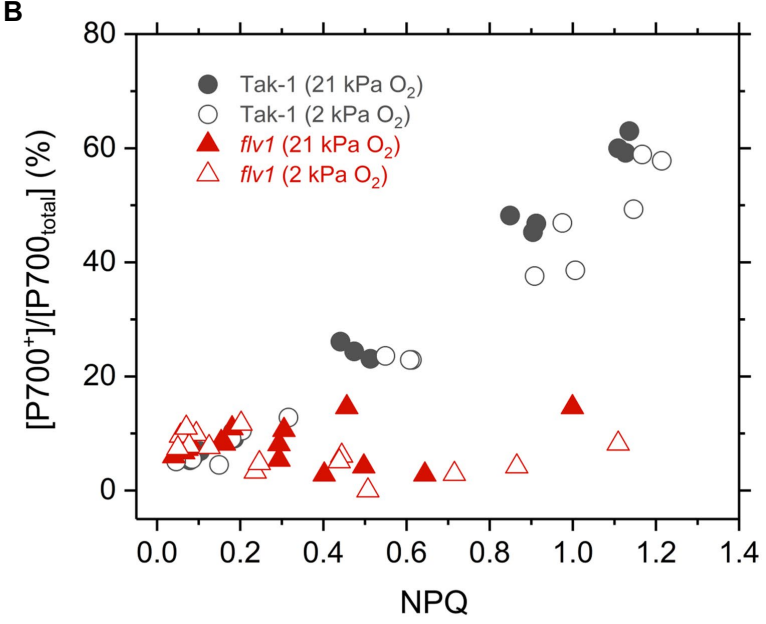

C

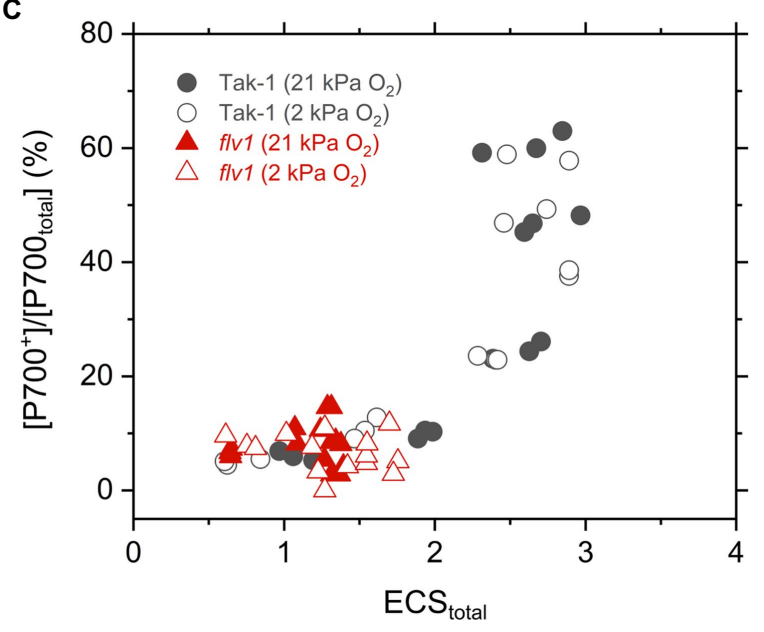

FIGURE 7 | Relationships of P700 oxidation with inferred reduction level of plastoquinone pool (1-qL; A), NPQ (B), and thylakoid membrane potential reflected in $\mathrm{ECS}_{\text {total }}$ (C) in the liverwort M. polymorpha (Tak-1; black circles) and the mutant fIV 1 (red triangles). Experiments were performed under 21 (closed symbols) and $2 \mathrm{kPa} \mathrm{O}$ (open symbols). Data are derived from three independent measurements in Figures 3, 4, and 6. oxidation in addition to the function as the electron sink, as reflected in the higher NPQ and $\mathrm{ECS}_{\text {total }}$ in Tak-1 at both 21 and $2 \mathrm{kPa} \mathrm{O}$ (Figures 3, 6). Meanwhile, P700 oxidation did not depend on the thylakoid membrane potential where $\mathrm{ECS}_{\text {total }}$ was almost saturated (Figure 7C). This can be interpreted based on the modulation of the balance between $\Delta \mathrm{pH}$ and $\Delta \Psi$ (Strand and Kramer, 2014) because NPQ actually showed the linear relationship with P700 oxidation (Figure 5). Nevertheless, we could not exclude the possible impact of $\mathrm{O}_{2}$ via $\mathrm{FLV}$ at the electron acceptor side of PSI. Since the contributions of FLV and photorespiration to the $\mathrm{O}_{2}$-dependent electron sink should be related to the amount of Rubisco in the thalli, we assume that photorespiration possibly replaces FLV to function for P700 oxidation in some specific situations.

Photorespiration is likely to already occur in cyanobacteria (Eisenhut et al., 2008) but only started to function as an alternative electron sink following adaptation of oxygenic photosynthetic organisms to terrestrial habitats (Hanawa et al., 2017), which was presumably enabled by the increase in the atmospheric $\mathrm{O}_{2}$ partial pressure. However, when basal land plants emerged, approximately 0.5 Gayears ago, atmospheric $\mathrm{O}_{2}$ partial pressure was still low (ca. $2 \mathrm{kPa})$ and $\mathrm{CO}_{2}$ partial pressures remained high $(>1 \mathrm{kPa}$; Kasting, 1987; Berner and Kothavala, 2001). Therefore, photorespiration would not have functioned at significant rates during the time when some green algae are acclimating the terrestrial conditions and evolving into the basal land plants. Such a situation possibly has been a reason why FLV plays a key role for the protection of PSI against excess light energy.

The molecular mechanism for the regulation of photosynthetic electron transport by PGR5 and PGRL1 is still under debate. PGR5 was first designated as a component essential for the antimycin-sensitive pathway of cyclic electron transport around PSI (Munekage et al., 2002). In this hypothetical model, the inability to oxidize P700 in pgr5 mutants could be explained by dysfunctional "photosynthetic control," due to the lack of effective $\Delta \mathrm{pH}$ generation by cyclic electron transport (Yamori and Shikanai, 2016). One problem that should be noted is the difficulty in measuring cyclic electron transport in vivo. The in vivo activity of cyclic electron transport has been often measured using the effective quantum yield of PSI, the so-called $\mathrm{Y}(\mathrm{I})$, which is easily overestimated when abundant plastocyanin is in its oxidized form (Furutani et al., 2020a). This is the reason why high $\mathrm{Y}(\mathrm{I})$ over $\mathrm{Y}(\mathrm{II})$ values were recorded on heterologous expression of FLV in Arabidopsis and rice mutants deficient in PGR5 (Yamamoto et al., 2016; Wada et al., 2018). That is, $\mathrm{Y}(\mathrm{I})$ can be misinterpreted when P700 is kept oxidized (Furutani et al., 2020a). Another hypothetical model has been proposed for the physiological function of PGR5, based on the higher $g_{\mathrm{H}}{ }^{+}$in the pgr5 mutants than in wild- type plants (Kanazawa et al., 2017; Rantala et al., 2020). Since $\Delta \mathrm{pH}$ is controlled not only by pumping $\mathrm{H}^{+}$into the thylakoid lumen through photosynthetic electron transport but also by narrowing the leak of $\mathrm{H}^{+}$from the lumen to the stroma (Rott et al., 2011). That is, PGR5 may be a regulatory factor for $\mathrm{H}^{+}$leakage across thylakoid membranes. This model could equally explain the inability of pgr5 mutants to oxidize P700, in the same 
way as the cyclic electron transport model. In C. reinhardtii, the amount of FNR attached to the thylakoid membrane decreased in the mutant deficient in pgr5 (Mosebach et al., 2017). Further, it has been recently found that the pgr5 mutant possesses the dysfunctional Cyt $b_{6} f$ complex in C. reinhardtii, which is assumed to be a cause of lower $\Delta \mathrm{pH}$ in the mutant (Buchert et al., 2020). The exact molecular function of PGR5 remains to be uncovered in future work.

\section{DATA AVAILABILITY STATEMENT}

The original contributions presented in the study are included in the article/Supplementary Material, further inquiries can be directed to the corresponding author.

\section{AUTHOR CONTRIBUTIONS}

$\mathrm{CM}$ conceived the research plan. GS and $\mathrm{HH}$ performed all experiments. GS provided assistances to $\mathrm{HH}$. SW, GH, and YM provided assistances to GS. GS, HH, and CM designed

\section{REFERENCES}

Alboresi, A., Storti, M., and Morosinotto, T. (2019). Balancing protection and efficiency in the regulation of photosynthetic electron transport across plant evolution. New Phytol. 221, 105-109. doi: 10.1111/nph.15372

Allahverdiyeva, Y., Isojarvi, J., Zhang, P., and Aro, E. M. (2015). Cyanobacterial oxygenic photosynthesis is protected by flavodiiron proteins. Life 5, 716-743. doi: $10.3390 /$ life 5010716

Allahverdiyeva, Y., Mustila, H., Ermakova, M., Bersanini, L., Richaud, P., Ajlani, G., et al. (2013). Flavodiiron proteins Flv1 and Flv3 enable cyanobacterial growth and photosynthesis under fluctuating light. Proc. Natl. Acad. Sci. U. S. A. 110, 4111-4116. doi: 10.1073/pnas.1221194110

Aro, E. M., Gerbaud, A., and Andre, M. (1984). $\mathrm{CO}_{2}$ and $\mathrm{O}_{2}$ exchange in two mosses, Hypnum cupressiforme and Dicranum scoparium. Plant Physiol. 76, 431-435. doi: 10.1104/pp.76.2.431

Badger, M. R., and Spalding, M. H. (2000). "CO2 acquisition, concentration and fixation in cyanobacteria and algae," in Photosynthesis: Physiology and Metabolism. eds. R. C. Leegood, T. D. Sharkey and CaemmererS. von (Dordrecht: Springer Netherlands), 369-397.

Badger, M. R., von Caemmerer, S., Ruuska, S., and Nakano, H. (2000). Electron flow to oxygen in higher plants and algae: rates and control of direct photoreduction (Mehler reaction) and rubisco oxygenase. Philos. Trans. R. Soc. B Biol. Sci. 355, 1433-1446. doi: 10.1098/rstb.2000.0704

Baker, N. R. (2008). Chlorophyll fluorescence: a probe of photosynthesis in vivo. Annu. Rev. Plant Biol. 59, 89-113. doi: 10.1146/annurev.arplant.59.032607.092759

Baker, N. R., Harbinson, J., and Kramer, D. M. (2007). Determining the limitations and regulation of photosynthetic energy transduction in leaves. Plant Cell Environ. 30, 1107-1125. doi: 10.1111/j.1365-3040.2007.01680.x

Bauwe, H., Hagemann, M., and Fernie, A. R. (2010). Photorespiration: players, partners and origin. Trends Plant Sci. 15, 330-336. doi: 10.1016/j. tplants.2010.03.006

Berner, R. A., and Kothavala, Z. (2001). Geocarb III: A revised model of atmospheric $\mathrm{CO}_{2}$ over phanerozoic time. Am. J. Sci. 301, 182-204. doi: 10.2475/ajs.301.2.182

Bowman, J. L., Floyd, S. K., and Sakakibara, K. (2007). Green genes-comparative genomics of the green branch of life. Cell 129, 229-234. doi: 10.1016/j. cell.2007.04.004

Buchert, F., Mosebach, L., Gäbelein, P., and Hippler, M. (2020). PGR5 is required for efficient $\mathrm{Q}$ cycle in the cytochrome $b_{6} f$ complex during cyclic electron flow. Biochem. J. 477, 1631-1650. doi: 10.1042/BCJ20190914 experiments and analyzed the data, and GS wrote the article with supports by $\mathrm{GH}$ and $\mathrm{CM}$. All authors contributed to the article and approved the submitted version.

\section{FUNDING}

This work was supported by the Core Research for Evolutional Science and Technology of Japan Science and Technology Agency, Japan (grant number JPMJCR1503 to CM) and the Japan Society for the Promotion of Science (grant number 16 J03443 and A20J001050 to GS), and BBSRC (grant number $\mathrm{BB} / \mathrm{R} 004838 / 1$ to $\mathrm{GH})$.

\section{SUPPLEMENTARY MATERIAL}

The Supplementary Material for this article can be found online at: https://www.frontiersin.org/articles/10.3389/fpls.2021.668805/ full\#supplementary-material

Burlacot, A., Sawyer, A., Cuiné, S., Auroy-Tarrago, P., Blangy, S., Happe, T., et al. (2018). Flavodiiron-mediated $\mathrm{O}_{2}$ photoreduction links $\mathrm{H}_{2}$ production with $\mathrm{CO}_{2}$ fixation during the anaerobic induction of photosynthesis. Plant Physiol. 177, 1639-1649. doi: 10.1104/pp.18.00721

Chaux, F., Burlacot, A., Mekhalfi, M., Auroy, P., Blangy, S., Richaud, P., et al (2017). Flavodiiron proteins promote fast and transient $\mathrm{O}_{2}$ photoreduction in Chlamydomonas. Plant Physiol. 174, 1825-1836. doi: 10.1104/pp.17.00421

Cho, C., Kim, J.-M., Ishii, R., Hyeon, S.-B., and Suzuki, A. (1985). Effect of aminoacetonitrile on the $\mathrm{CO}_{2}$ exchange rate in rice leaves. Agric. Biol. Chem. 49, 2847-2850. doi: 10.1271/bbb1961.49.2847

Cruz, J. A., Sacksteder, C. A., Kanazawa, A., and Kramer, D. M. (2001). Contribution of electric field $(\Delta \psi)$ to steady-state transthylakoid proton motive force (pmf) in vitro and in vivo. Control of pmf parsing into $\Delta \psi$ and $\Delta \mathrm{pH}$ by ionic strength. Biochemistry 40, 1226-1237. doi: 10.1021/ bi0018741

DalCorso, G., Pesaresi, P., Masiero, S., Aseeva, E., Schünemann, D., Finazzi, G., et al. (2008). A complex containing PGRL1 and PGR5 is involved in the switch between linear and cyclic electron flow in Arabidopsis. Cell 132, 273-285. doi: 10.1016/j.cell.2007.12.028

Dann, M., and Leister, D. (2019). Evidence that cyanobacterial Sll1217 functions analogously to PGRL1 in enhancing PGR5-dependent cyclic electron flow. Nat. Commun. 10:5299. doi: 10.1038/s41467-019-13223-0

Dellero, Y., Jossier, M., Schmitz, J., Maurino, V. G., and Hodges, M. (2016). Photorespiratory glycolate-glyoxylate metabolism. J. Exp. Bot. 67, 3041-3052. doi: 10.1093/jxb/erw090

Driever, S. M., and Baker, N. R. (2011). The water-water cycle in leaves is not a major alternative electron sink for dissipation of excess excitation energy when $\mathrm{CO}_{2}$ assimilation is restricted. Plant Cell Environ. 34, 837-846. doi: $10.1111 / j .1365-3040.2011 .02288 . x$

Eisenhut, M., Ruth, W., Haimovich, M., Bauwe, H., Kaplan, A., and Hagemann, M. (2008). The photorespiratory glycolate metabolism is essential for cyanobacteria and might have been conveyed endosymbiontically to plants. Proc. Natl. Acad. Sci. U. S. A. 105, 17199-17204. doi: 10.1073/pnas.0807043105

Foyer, C., Furbank, R., Harbinson, J., and Horton, P. (1990). The mechanisms contributing to photosynthetic control of electron transport by carbon assimilation in leaves. Photosynth. Res. 25, 83-100. doi: 10.1007/BF00035457

Furutani, R., Ifuku, K., Suzuki, Y., Noguchi, K., Shimakawa, G., Wada, S., et al. (2020a). "P700 oxidation suppresses the production of reactive oxygen species in photosystem I," in Advances in Botanical Research. ed. T. Hisabori (Cambridge, MA, USA: Academic Press), 151-176. 
Furutani, R., Makino, A., Suzuki, Y., Wada, S., Shimakawa, G., and Miyake, C. (2020b). Intrinsic fluctuations in transpiration induce photorespiration to oxidize P700 in photosystem I. Plan. Theory 9:1761. doi: 10.3390/plants9121761

Gamborg, O. L., Miller, R. A., and Ojima, K. (1968). Nutrient requirements of suspension cultures of soybean root cells. Exp. Cell Res. 50, 151-158. doi: 10.1016/0014-4827(68)90403-5

Genty, B., Briantais, J.-M., and Baker, N. R. (1989). The relationship between the quantum yield of photosynthetic electron transport and quenching of chlorophyll fluorescence. Biochim. Biophys. Acta Gen. Subj. 990, 87-92. doi: 10.1016/S0304-4165(89)80016-9

Gerotto, C., Alboresi, A., Meneghesso, A., Jokel, M., Suorsa, M., Aro, E.-M., et al. (2016). Flavodiiron proteins act as safety valve for electrons in Physcomitrella patens. Proc. Natl. Acad. Sci. U. S. A. 113, 12322-12327. doi: 10.1073/pnas.1606685113

Hagemann, M., Fernie, A. R., Espie, G. S., Kern, R., Eisenhut, M., Reumann, S., et al. (2013). Evolution of the biochemistry of the photorespiratory C2 cycle. Plant Biol. 15, 639-647. doi: 10.1111/j.1438-8677.2012.00677.x

Hanawa, H., Ishizaki, K., Nohira, K., Takagi, D., Shimakawa, G., Sejima, T., et al. (2017). Land plants drive photorespiration as higher electron-sink: comparative study of post-illumination transient $\mathrm{O}_{2}$-uptake rates from liverworts to angiosperms through ferns and gymnosperms. Physiol. Plant. 161, 138-149. doi: 10.1111/ppl.12580

Harbinson, J., and Woodward, F. I. (1987). The use of light-induced absorbance changes at $820 \mathrm{~nm}$ to monitor the oxidation state of P-700 in leaves. Plant Cell Environ. 10, 131-140. doi: 10.1111/1365-3040.ep11602090

Helman, Y., Barkan, E., Eisenstadt, D., Luz, B., and Kaplan, A. (2005). Fractionation of the three stable oxygen isotopes by oxygen-producing and oxygen-consuming reactions in photosynthetic organisms. Plant Physiol. 138, 2292-2298. doi: 10.1104/pp.105.063768

Helman, Y., Tchernov, D., Reinhold, L., Shibata, M., Ogawa, T., Schwarz, R., et al. (2003). Genes encoding A-type flavoproteins are essential for photoreduction of $\mathrm{O}_{2}$ in cyanobacteria. Curr. Biol. 13, 230-235. doi: 10.1016/ S0960-9822(03)00046-0

Johnson, M. P., and Ruban, A. V. (2014). Rethinking the existence of a steady-state $\Delta \psi$ component of the proton motive force across plant thylakoid membranes. Photosynth. Res. 119, 233-242. doi: 10.1007/ s11120-013-9817-2

Johnson, X., Steinbeck, J., Dent, R. M., Takahashi, H., Richaud, P., Ozawa, S.-I., et al. (2014). Proton gradient regulation 5-mediated cyclic electron flow under ATP- or redox-limited conditions: a study of $\triangle$ ATPase pgr5 and $\Delta r b c L$ pgr5 mutants in the green alga Chlamydomonas reinhardtii. Plant Physiol. 165, 438-452. doi: 10.1104/pp.113.233593

Jokel, M., Johnson, X., Peltier, G., Aro, E.-M., and Allahverdiyeva, Y. (2018). Hunting the main player enabling Chlamydomonas reinhardtii growth under fluctuating light. Plant J. 94, 822-835. doi: 10.1111/tpj.13897

Kanazawa, A., and Kramer, D. M. (2002). In vivo modulation of nonphotochemical exciton quenching (NPQ) by regulation of the chloroplast ATP synthase. Proc. Natl. Acad. Sci. U. S. A. 99, 12789-12794. doi: 10.1073/pnas.182427499

Kanazawa, A., Ostendorf, E., Kohzuma, K., Hoh, D., Strand, D. D., Sato-Cruz, M., et al. (2017). Chloroplast ATP synthase modulation of the thylakoid proton motive force: implications for photosystem I and photosystem II photoprotection. Front. Plant Sci. 8:719. doi: 10.3389/fpls.2017.00719

Kasting, J. F. (1987). Theoretical constraints on oxygen and carbon dioxide concentrations in the Precambrian atmosphere. Precambrian Res. 34, 205-229. doi: 10.1016/0301-9268(87)90001-5

Klughammer, C., and Schreiber, U. (1994). An improved method, using saturating light pulses, for the determination of photosystem I quantum yield via $\mathrm{P} 700^{+}$-absorbance changes at $830 \mathrm{~nm}$. Planta 192, 261-268. doi: 10.1007/ BF01089043

Klughammer, C., Siebke, K., and Schreiber, U. (2013). Continuous ECS-indicated recording of the proton-motive charge flux in leaves. Photosynth. Res. 117, 471-487. doi: 10.1007/s11120-013-9884-4

Kramer, D. M., Cruz, J. A., and Kanazawa, A. (2003). Balancing the central roles of the thylakoid proton gradient. Trends Plant Sci. 8, 27-32. doi: 10.1016/S1360-1385(02)00010-9

Margulis, K., Zer, H., Lis, H., Schoffman, H., Murik, O., Shimakawa, G., et al. (2020). Over expression of the cyanobacterial Pgr5-homologue leads to pseudoreversion in a gene coding for a putative esterase in Synechocystis 6803. Life 10:174. doi: 10.3390/life10090174
Miyake, C. (2010). Alternative electron flows (water-water cycle and cyclic electron flow around PSI) in photosynthesis: molecular mechanisms and physiological functions. Plant Cell Physiol. 51, 1951-1963. doi: 10.1093/pcp/ pcq173

Mosebach, L., Heilmann, C., Mutoh, R., Gäbelein, P., Steinbeck, J., Happe, T., et al. (2017). Association of Ferredoxin:NADP ${ }^{+}$oxidoreductase with the photosynthetic apparatus modulates electron transfer in Chlamydomonas reinhardtii. Photosynth. Res. 134, 291-306. doi: 10.1007/s11120-017-0408-5

Munekage, Y., Hojo, M., Meurer, J., Endo, T., Tasaka, M., and Shikanai, T. (2002). PGR5 is involved in cyclic electron flow around photosystem $i$ and is essential for photoprotection in Arabidopsis. Cell 110, 361-371. doi: 10.1016/S0092-8674(02)00867-X

Nawrocki, W. J., Tourasse, N. J., Taly, A., Rappaport, F., and Wollman, F.-A. (2015). The plastid terminal oxidase: its elusive function points to multiple contributions to plastid physiology. Annu. Rev. Plant Biol. 66, 49-74. doi: 10.1146/annurev-arplant-043014-114744

Nikkanen, L., Solymosi, D., Jokel, M., and Allahverdiyeva, Y. (2021). Regulatory electron transport pathways of photosynthesis in cyanobacteria and microalgae: recent advances and biotechnological prospects. Physiol. Plant. doi: 10.1111/ ppl.13404 [Epub ahead of print]

Orr, D. J., Alcântara, A., Kapralov, M. V., Andralojc, P. J., Carmo-Silva, E., and Parry, M. A. J. (2016). Surveying rubisco diversity and temperature response to improve crop photosynthetic efficiency. Plant Physiol. 172, 707-717. doi: 10.1104/pp.16.00750

Peltier, G., and Thibault, P. (1985). Light-dependent oxygen uptake, glycolate, and ammonia release in L-methionine sulfoximine-treated Chlamydomonas. Plant Physiol. 77, 281-284. doi: 10.1104/pp.77.2.281

Rantala, S., Lempiäinen, T., Gerotto, C., Tiwari, A., Aro, E.-M., and Tikkanen, M. (2020). PGR5 and NDH-1 systems do not function as protective electron acceptors but mitigate the consequences of PSI inhibition. Biochim. Biophys. Acta Bioenerg. 1861:148154. doi: 10.1016/j.bbabio.2020.148154

Raven, J. A., Osborne, B. A., and Johnston, A. M. (1985). Uptake of $\mathrm{CO}_{2}$ by aquatic vegetation. Plant Cell Environ. 8, 417-425. doi: 10.1111/j.1365-3040.1985. tb01677.x

Romão, C. V., Vicente, J. B., Borges, P. T., Frazão, C., and Teixeira, M. (2016). The dual function of flavodiiron proteins: oxygen and/or nitric oxide reductases. J. Biol. Inorg. Chem. 21, 39-52. doi: 10.1007/s00775-015-1329-4

Rott, M., Martins, N. F., Thiele, W., Lein, W., Bock, R., Kramer, D. M., et al. (2011). ATP synthase repression in tobacco restricts photosynthetic electron transport, $\mathrm{CO}_{2}$ assimilation, and plant growth by overacidification of the thylakoid lumen. Plant Cell 23, 304-321. doi: 10.1105/tpc.110.079111

Sétif, P., Shimakawa, G., Krieger-Liszkay, A., and Miyake, C. (2020). Identification of the electron donor to flavodiiron proteins in Synechocystis sp. PCC 6803 by in vivo spectroscopy. Biochim. Biophys. Acta Bioenerg. 1861:148256. doi: 10.1016/j.bbabio.2020.148256

Sacksteder, C. A., and Kramer, D. M. (2000). Dark-interval relaxation kinetics (DIRK) of absorbance changes as a quantitative probe of steady-state electron transfer. Photosynth. Res. 66, 145-158. doi: 10.1023/A:1010785912271

Santana-Sanchez, A., Solymosi, D., Mustila, H., Bersanini, L., Aro, E.-M., and Allahverdiyeva, Y. (2019). Flavodiiron proteins 1-to-4 function in versatile combinations in $\mathrm{O}_{2}$ photoreduction in cyanobacteria. Elife 8:e45766. doi: 10.7554/eLife.45766

Schreiber, U., Schliwa, U., and Bilger, W. (1986). Continuous recording of photochemical and non-photochemical chlorophyll fluorescence quenching with a new type of modulation fluorometer. Photosynth. Res. 10, 51-62. doi: 10.1007/BF00024185

Sejima, T., Takagi, D., Fukayama, H., Makino, A., and Miyake, C. (2014). Repetitive short-pulse light mainly inactivates photosystem I in sunflower leaves. Plant Cell Physiol. 55, 1184-1193. doi: 10.1093/pcp/pcu061

Selinski, J., and Scheibe, R. (2019). Malate valves: old shuttles with new perspectives. Plant Biol. 21, 21-30. doi: 10.1111/plb.12869

Shaku, K., Shimakawa, G., Hashiguchi, M., and Miyake, C. (2016). Reductioninduced suppression of electron flow (RISE) in the photosynthetic electron transport system of Synechococcus elongatus PCC 7942. Plant Cell Physiol. 57, 1443-1453. doi: 10.1093/pcp/pcv198

Shimakawa, G., Ishizaki, K., Tsukamoto, S., Tanaka, M., Sejima, T., and Miyake, C. (2017). The liverwort, Marchantia, drives alternative electron flow using a flavodiiron protein to protect PSI. Plant Physiol. 173, 1636-1647. doi: 10.1104/ pp. 16.01038 
Shimakawa, G., and Miyake, C. (2018a). Changing frequency of fluctuating light reveals the molecular mechanism for P700 oxidation in plant leaves. Plant Direct 2:e0073. doi: 10.1002/pld3.73

Shimakawa, G., and Miyake, C. (2018b). Oxidation of P700 ensures robust photosynthesis. Front. Plant Sci. 9:1617. doi: 10.3389/fpls.2018.01617

Shimakawa, G., Shaku, K., and Miyake, C. (2016). Oxidation of P700 in photosystem I is essential for the growth of cyanobacteria. Plant Physiol. 172, 1443-1450. doi: 10.1104/pp.16.01227

Storti, M., Alboresi, A., Gerotto, C., Aro, E.-M., Finazzi, G., and Morosinotto, T. (2019). Role of cyclic and pseudo-cyclic electron transport in response to dynamic light changes in Physcomitrella patens. Plant Cell Environ. 42, 1590-1602. doi: 10.1111/pce. 13493

Storti, M., Segalla, A., Mellon, M., Alboresi, A., and Morosinotto, T. (2020). Regulation of electron transport is essential for photosystem I stability and plant growth. New Phytol. 228, 1316-1326. doi: 10.1111/nph.16643

Strand, D. D., and Kramer, D. M. (2014). "Control of non-photochemical exciton quenching by the proton circuit of photosynthesis," in Non-Photochemical Quenching and Energy Dissipation in Plants, Algae and Cyanobacteria. eds. B. Demmig-Adams, G. Garab, W. A. III and U. Govindjee (Dordrecht: Springer Netherlands), 387-408.

Suorsa, M., Jarvi, S., Grieco, M., Nurmi, M., Pietrzykowska, M., Rantala, M., et al. (2012). PROTON GRADIENT REGULATION5 is essential for proper acclimation of Arabidopsis photosystem I to naturally and artificially fluctuating light conditions. Plant Cell 24, 2934-2948. doi: 10.1105/tpc.112.097162

Vicente, J. B., Gomes, C. M., Wasserfallen, A., and Teixeira, M. (2002). Module fusion in an A-type flavoprotein from the cyanobacterium Synechocystis condenses a multiple-component pathway in a single polypeptide chain. Biochem. Biophys. Res. Commun. 294, 82-87. doi: 10.1016/S0006-291X(02)00434-5

Wada, S., Yamamoto, H., Suzuki, Y., Yamori, W., Shikanai, T., and Makino, A. (2018). Flavodiiron protein substitutes for cyclic electron flow without competing $\mathrm{CO}_{2}$ assimilation in rice. Plant Physiol. 176, 1509-1518. doi: 10.1104/pp.17.01335

Witt, H. T. (1979). Energy conversion in the functional membrane of photosynthesis. Analysis by light pulse and electric pulse methods. The central role of the electric field. Biochim. Biophys. Acta 505, 355-427. doi: 10.1016/0304-4173(79)90008-9

Yamamoto, H., Takahashi, S., Badger, M. R., and Shikanai, T. (2016). Artificial remodelling of alternative electron flow by flavodiiron proteins in Arabidopsis. Nat. Plants 2:16012. doi: 10.1038/nplants.2016.12

Yamori, W., Makino, A., and Shikanai, T. (2016). A physiological role of cyclic electron transport around photosystem I in sustaining photosynthesis under fluctuating light in rice. Sci. Rep. 6:20147. doi: 10.1038/srep20147

Yamori, W., and Shikanai, T. (2016). Physiological functions of cyclic electron transport around photosystem I in sustaining photosynthesis and plant growth. Annu. Rev. Plant Biol. 67, 81-106. doi: 10.1146/annurevarplant-043015-112002

Zivcak, M., Brestic, M., Kunderlikova, K., Sytar, O., and Allakhverdiev, S. I. (2015). Repetitive light pulse-induced photoinhibition of photosystem I severely affects $\mathrm{CO}_{2}$ assimilation and photoprotection in wheat leaves. Photosynth. Res. 126, 449-463. doi: 10.1007/s11120-015-0121-1

Conflict of Interest: The authors declare that the research was conducted in the absence of any commercial or financial relationships that could be construed as a potential conflict of interest.

Publisher's Note: All claims expressed in this article are solely those of the authors and do not necessarily represent those of their affiliated organizations, or those of the publisher, the editors and the reviewers. Any product that may be evaluated in this article, or claim that may be made by its manufacturer, is not guaranteed or endorsed by the publisher.

Copyright (c) 2021 Shimakawa, Hanawa, Wada, Hanke, Matsuda and Miyake. This is an open-access article distributed under the terms of the Creative Commons Attribution License (CC BY). The use, distribution or reproduction in other forums is permitted, provided the original author(s) and the copyright owner(s) are credited and that the original publication in this journal is cited, in accordance with accepted academic practice. No use, distribution or reproduction is permitted which does not comply with these terms. 